\title{
DEFINING OMNIPOTENCE
}

In a paper published elsewhere in this issue ("The Impossibility of Defining "Omnipotence" '), Richard R. La Croix argues that it is impossible to produce a satisfactory general definition of omnipotence (i.e., one which generalizes universally over persons). And he suggests that theologians, and people with similar interests, should turn their attention away from this project and toward that of formulating an analysis of God is omnipotent. In this paper I will discuss La Croix's argument for the impossibility thesis, but I will have nothing at all to say about his latter suggestion.

The general strategy of La Croix's argument seems to me to go like this. He sets out a general schema for definitions of omnipotence, and a set of four conditions which any definition must satisfy if it is not to lead to logical absurdities, be theologically irrelevant, or be vacuous. He then argues that any definition which satisfies the first two conditions must fail to satisfy either the third or the fourth condition. And this stage of the argument is carried forward by considering a type of definition which satisfies conditions 1 and 2 , but not 3 , and then asking how it might be amended to remedy this defect. At that point La Croix argues that the only possible amendments which will bring it into conformity with condition 3 must also guarantee that it fails to satisfy condition 4 . And that, of course, yields the impossibility thesis. (In this paper I will give a further account of only those parts of a Croix's argument which I intend to criticize in some detail. Readers are urged to refer to La Croix's own article for a full statement of his argument.)

I believe that La Croix's argument is inconclusive. It has two related weak points. The first is that his general schema for definitions of 'omnipotence' is defective. The second is that he fails to show that his way of remedying the initial defect in his sample definition (or type of definition) is the only possible way. And so, even if his own amended attempt falls prey to the objections which he urges, it does not show that all such attempts must similarly fail. 
I hope to argue these points constructively, by producing a definition of 'omnipotence' which, it seems to me, avoids all of La Croix's difficulties. I am not sure that this definition is completely satisfactory, though I think it has a pretty good chance of being so. At the very least, however, it should reassure us that $\mathrm{La}$ Croix has not proved this project to be impossible.

Well, to begin. First I must say a little about what I have called La Croix's general schema for definitions of 'omnipotence': He says "Presumably any definition, $D$, of omnipotence will quantify over individuals and states of affairs ... $D$ will make a statement to the effect that with respect to any individual $x$ and any state of affairs $s$, the sentence ' $x$ is omnipotent' equals by definition or is logically equivalent to the sentence 'if $s$ satisfies a certain set of conditions $C$ then $x$ is able to bring about $s^{\prime}$... This presumably describes the general structure and content minimally necessary to any definition, $D$, of omnipotence." And in a footnote La Croix allows that a definition may quantify over actions rather than states of affairs.

I think that this schema is not correct as it stands. It requires emendation, and the change turns out to be rather important. A satisfactory definition of omnipotence will not quantify over states of affairs (or actions), but rather either over propositions or else over sets of possible states of affairs (or sets of possible actions). Let me explain my reason for that.

Let us imagine a person who sets out to test the alleged omnipotence of God in a crudely empirical way. He issues various challenges to God, and waits to see how God responds. So one day he shouts, "Can you bring it about that China is invaded by a Swiss army?" And suppose that God replies, "Yes, I can." And, sure enough, the next day a Swiss army crosses the Chinese border from the north. Now, assuming at least that the invasion was not a lucky coincidence but was really brought about by God, it certainly looks as though God would have met the challenge. So far, at least, the challenger has failed to discover that God lacks omnipotence. And God has apparently met this challenge by bringing about a certain state of affairs. But has He brought about the state of affairs which was identified, or referred to, in the challenge? I think not, for the following reason.

God, we are supposing, brought about an invasion of China from the north. But He would have met the challenge equally well if He had brought a Swiss army into China from the south. China's being invaded from the south, however, does not seem to be the same state of affairs as China's being invaded from the north. If that is so, however, then they cannot both be the 
state of affairs referred to in the challenge. But there seems to be no reason to pick out one of these rather than the other as being that state of affairs. So it seems likely that neither of these states of affairs, whose actuality would satisfy the challenge, is the state of affairs referred to in the challenge.

Once we see this, it may be obvious to us that the original challenge does not identify any state of affairs at all, and that is why God's action does not bring about that state of affairs. The heart of the challenge is a proposition, China is invaded by a Swiss army, which may also be put as a nominalization, China's being invaded by a Swiss army. But this proposition would be rendered true by any one of a large number, maybe an infinite number, of distinct possible states of affairs. If the challenger refers to, or identifies, any states of affairs at all, then he refers to this whole set of possible states of affairs. And God will meet that challenge successfully if He brings into actuality any one (not all) of that set of possible states of affairs, any state of affairs which would render true the proposition embedded in the challenge.

Now, I think that we can construe a definition of omnipotence as generalizing over challenges of this sort, as saying that any person is omnipotent if and only if he is able to meet every challenge - or, more accurately, if he is able to meet every challenge which satisfies certain conditions of internal coherence, etc. To put this somewhat more formally, let us say that a state of affairs, $S$, satisfies a proposition, $p$, if and only if $p$ could not fail to be true if $S$ were actually to obtain. Then I will say that a definition of omnipotence will quantify universally over persons and over propositions, and the definition will say that an agent is omnipotent if and only if for any proposition which meets a certain condition the agent can bring about some state of affairs which satisfies that proposition.

This schema will yield an actual definition if we specify the conditions to be placed on the propositions over which it quantifies. What are the parts of that condition?

One widely recognized condition, which is roughly equivalent to La Croix's first condition is the following:

(C1) There is some possible state of affairs which would satisfy $p$, and such that it is not a necessary truth that no agent has brought it about that this state of affairs obtains.

This condition rules out propositions which are necessarily unsatisfiable by the 
action of an agent. As La Croix points out, it is widely (though not universally) recognized among philosophers who have written about omnipotence that this notion does not require the power to bring about logical absurdities. So, for example, if there are some properties which are essential to Charlemagne and which are of such a sort that it is not logically possible that Charlemagne should have been a swordfish, then it does no damage to the omnipotence of God to recognize that God could not have created Charlemagne as a swordfish (though He could, presumably, have created a swordfish instead of Charlemagne).

Well, (C1) is the first restriction to be incorporated into our definition. Is it sufficient? La Croix would perhaps argue that it is not. For he holds that "there is a kind of state of affairs whose description is not self-contradictory and which it is logically possible for some agent or other to bring about but which it is logically impossible for some particular agent to bring about. So, for example, a state of affairs not brought about by an omnipotent being is a state of affairs whose description is not self-contradictory and which it is logically impossible for an omnipotent being to bring about." La Croix formulates his second condition to rule out such cases. Perhaps I should have some analogue of that condition. Or should I?

In the first place, we might notice something odd about the way in which La Croix's argument goes at this point. He claims that a state of affairs not brought about by an omnipotent being is one which it is not possible for an omnipotent being to bring about. Is there any reason to believe that to be true? I doubt it. Suppose that my neighbor sets fire to his house, and I have nothing to do with it. A certain state of affairs will then obtain, a state of affairs which may be reported in the newspaper the next day as the burning down of my neighbor's house. And one property of this state of affairs will be that it was brought about by my neighbor and not by me. But suppose someone wonders whether I could have brought about that state of affairs, whether I had the power to do it. And why should not the answer to that question be yes? I am as handy with matches as is my neighbor. I, too, have the power to set fire to his house. Of course, if I had been the one to set fire to his house then the resulting state of affairs would have had a property which (on our initial supposition) it does not actually have. But so what? If I had been a lawyer I would have had a property which, as it happens, I do not actually have. I does not follow that I could not have been a lawyer, that I had no power to become a lawyer. So from the fact that if $I$, rather than 
someone else, had actualized a certain state of affairs it would have had a property which it does not actually have it does not follow that I had no power to actualize it.

La Croix's argument seems to involve a confusion at this point. We can often refer to a thing satisfactorily enough be way of some non-essential property of that thing. So we may refer to a certain lady, quite accurately, as "the tallest lady in Des Moines". And we may then notice that the sentence, "The tallest lady in Des Moines is not the tallest lady in Des Moines", could not possibly be true (given, of course, the normal interpretation of its parts). That it so, but it is nevertheless easily possible that the tallest lady in Des Moines should not be the tallest lady in Des Moines. She would cease to be the tallest lady in Des Moines, for example, if a taller than she should move there. And she might never have been the tallest lady in Des Moines if she had eaten less heartily when she was young. The property of being the tallest lady in Des Moines is not an essential property of the person who has it, and so that very person might have failed to have that property. So also, it seems to me, the property of being brought about by a being who is not omnipotent is probably not an essential property of any state of affairs which happens to have it. And if that is so then there is no reason to believe that an omnipotent being would not have the power to bring about such states of affairs.

This observation may be sufficient to solve the problem which troubles La Croix at this point. But there is also a second, and more powerful, reason for thinking that a satisfactory definition need not contain any analogue of La Croix's second condition. And this reason would hold even if it should be the case that being brought about by such-and-such an agent (or kind of agent) were an essential property of every state of affairs. This reason, briefly, is that La Croix's problem here has no application to definitions which follow. my proposed schema. My definition does not require that an omnipotent being be able to actualize all states of affairs of a certain type, but rather that for all propositions of a certain type such a being can actualize some state of affairs which satisfies them. So the discovery of some state of affairs which the candidate cannot actualize may not, of itself, damage his claim to omnipotence. That will depend upon whether there is some permissible proposition such that this state of affairs is the only one which will satisfy it. And it is not at all clear that there is any such proposition.

Consider, for example, the following: 
(1) Hidden Valley is flooded.

Can God, if $\mathrm{He}$ is omnipotent, bring about some state of affairs which satisfies (1)? Well, yes, I suppose so. Maybe, for example, He can cause a small avalanche which will dam Hidden Valley Creek, thus causing some flooding in the valley. So far, so good.

At this point, however, La Croix would no doubt insist that he is not concerned with propositions such as (1), but rather with some which include a proposition similar to (1) plus some specification of the agent who brings about the state of affairs satisfying the included proposition. So we get

A non-omnipotent being brings it about that Hidden Valley is flooded.

And La Croix apparently believes that it is not possible for an omnipotent being to bring about a state of affairs which satisfies (2). Presumably it is the reference, within (2), to a non-omnipotent being which leads him to the belief. It seems to me, however, that this is a mistake. (2) says, in effect, that some non-omnipotent being brings about some state of affairs which satisfies (1). It does not say anything, however, about what being (if any) brings about the state of affairs which satisfies (2). And, so far as I can see, it is quite possible that God, if $\mathrm{He}$ is omnipotent, may bring about a state of affairs which satisifies (2). He may, for example, cause a beaver to build a dam across Hidden Valley Creek. The beaver, presumably, is not omnipotent. Hence it will be the case that a non-omnipotent being, the beaver, has brought about the flooding of Hidden Valley. And that more inclusive state of affairs will have been brought about by God. Furthermore, not only could this be done by God, but it could be done by any agent who was omnipotent. So (2) is apparently not the proposition which we were seeking.

Another interesting candidate is

(3) Some non-omnipotent being freely (by free will) brings it about that Hidden Valley is flooded.

I think that some state of affairs might obtain which would satisfy (3). Some human being, for example, might dam Hidden Valley Creek, and if he did so (and did it freely) then (3) would be satisfied. Could God bring about some state of affairs which satisfies (3)?

I believe that God, regardless of whether He is omnipotent, could not 
bring about any state of affairs which satisfies (3). That is because I believe that if someone freely does one thing rather than another then no one (or nothing) causes it to be the case, or brings it about, that he does the one thing rather than the other. And so, it seems to me, neither God nor anyone else can bring it about that some person freely dams Hidden Valley Creek. That, however, is a difficult thesis, much disputed among philosophers. It would not be germane to our topic here to pursue it further. For (3) is innoccuous regardless of how that thesis turns out.

If, as some philosophers claim, free will is compatible with determinism, causation, etc., then there is no reason to think that God, if He is omnipotent, cannot bring about a state of affairs which satisfies (3). For He can simply cause some human being to dam Hidden Valley Creek, etc. In this case, (3) will be handled just like (2).

If, on the other hand, I should be right in thinking that free will is incompatible with determinism, causation, etc., then we must take a different tack. The important point to notice here is that, if there is this incompatibility, then the agent himself is not the cause of his doing the one thing rather than the other. He performs his own action, of course, but he does not cause himself to perform that action, nor bring it about that he performs this action. Rather, on this view, his doing of that action freely is not brought about at all, either by himself or by someone else.

We need to use here a distinction similar to one which we used with reference to (1) and (2). A beaver, I said, might bring about a state of affairs which satisfied (1). If he did so, then there would also obtain a state of affairs which satisfies (2). We need not think, however, that this second state of affairs must, like the first one, also be brought about by the beaver. No, it may be God (or some other agent), and not the beaver, who causes the beaver to build the dam, etc. Now, when we come to (3) we consider the possibility that, say, a human being may freely bring about the state of affairs which satisfies (1). If he does so, then there will also obtain a state of affairs which satisfies (3). But just as we need not suppose that the beaver brings about the state of affairs which satisfies (2), so here we need not assume that the human being brings about the state of affairs which satisfies (3). Indeed, the incompatibility thesis requires that such a state of affairs be brought about by no one at all. In my view, therefore, it is readily possible that there should obtain some states of affairs - those which involve the free acts of some agents - such that it is not possible that they be brought about at all. (This does not 
entail, incidentally, that such states of affairs occur 'by chance', randomly, etc.)

If all of this is so, then God cannot satisfy a challenge which is couched in terms of (3). That fact, however, will not damage His claim to omnipotence, as I define it, for (3) runs afoul of condition (C1). On the supposition we are here using it is a necessary truth that no agent can bring about any state of affairs which would satisfy (3). And so the discovery that this or that agent cannot do it has no bearing on whether such an agent is omnipotent.

This brings me to the last case I want to consider here. Going back to our discussion of (2), we may notice that while the beaver brings about the flooding of Hidden Valley, there is also a sense in which God causes of flooding (by causing the beaver to build a dam, etc.). And that may inspire us to construct

(4) A non-omnipotent being brings it about that Hidden Valley is flooded, and no omnipotent being brings it about that Hidden Valley is flooded.

Can God, If He is omnipotent, bring it about that some state of affairs satisfying (4) obtains?

I am inclined to think that no omnipotent being can bring about any such state of affairs. But what the significance of that fact may be is not altogether clear.

We should inquire first whether it is possible that (4) should be satisfied by any actual state of affairs. Given my view of freedom, I believe that it is possible (and that many such states of affairs actually obtain). But if the only states of affairs which can satisfy (4) involve some free action, then, given my view of freedom, it is not possible that any agent should bring about a state of affairs satisfying (4). In that case (4) could be handled just like (3).

Is it possible at all that (4) should be satisfied by some state of affairs which involves no free act of a non-omnipotent being? If it is a necessary truth that no such state of affairs can obtain, then it is also a necessary truth that no such state of affairs can be brought about by any agent. In that case (4) will be ruled out by (C1), and will do no damage to any agent's claim to omnipotence. Well, is it a necessary truth? I am not sure that it is, but I also am not at all sure that it is not. It has sometimes been claimed that it is necessarily true that God exists - that there is no possible world in which He does not exist. This view, though often challenged, is now being powerfully 
defended. ${ }^{1}$ If it should be true, and if it is also a necessary truth that God, if $\mathrm{He}$ exists, is omnipotent, then it seems likely that every state of affairs, except perhaps those which involve free will in some way, must be attributable in the end to an omnipotent being. And if that is so, then there cannot be a non-free-will satisfaction of (4).

On the other hand, perhaps it is not a necessary truth that God exists (or that any other omnipotent being exists). Maybe it is true that there exists some being with a plausible claim to omnipotence, but only contingently true. Or maybe for some other reason it turns out to be possible for (4) to be satisfied by some non-free-will state of affairs. How would things stand then? Would the fact that no omnipotent being could meet a challenge which involved (4) show that no being could be omnipotent?

It seems rather clear that it would not. For a failure to meet the challenge posed in (4) may be not be due to any lack of power, but rather to the fact that (4) simply decrees that it is not to be satisfied by certain types of agents. We wish, therefore, to exclude challenges based on propositions like (4) from the set of legitimate challenges which are relevant to assessments of power and omnipotence. But if it is possible that some agent could bring about a state of affairs satisfying (4), then (4) is not ruled out by ( $\mathrm{C} 1$ ). I therefore introduce another condition (which may, however, be redundant)

(C2) If $p$ entails that some proposition, $q$, is satisfied, and if it is not a necessary truth that no agent can have brought about the satisfaction of $q$, then $p$ does not exclude any agent, or class of agents, from among those which may have brought about the satisfaction of $q$.

And if (4) is not ruled out by (C1), then it will be excluded by (C2).

These two conditions, I believe now, are sufficient. My proposed general definition of omnipotence, then would run as follows:

For any agent, $n, n$ is omnipotent IFF for any proposition, $p$, which meets conditions (C1) and (C2) below, $n$ is able to bring about some state of affairs .which satisfies $p$. The two conditions on $p$ are: (C1) there is some possible state of affairs which would satisfy $p$, and such that it is not a necessary truth that no agent has brought it about that this state of affairs obtains, and (C2) if $p$ entails that some proposition, $q$, is satisfied, and if it is not a necessary truth that no agent can have brought about the satisfaction of $q$, then $p$ does 
not exclude any agent, or class of agent, from among those which may have brought about the satisfaction of $q$.

This definition, I think, meets the difficulties posed in the main part of La Croix's paper. It does not require an omnipotent being to perform logical absurdities. It does not allow an omnipotence claim to be defeated by stipulations (as in (4)) which arbitrarily exclude certain agents. And it does not entail that some clearly impotent being (such as La Croix's Mr. McEar) is omnipotent. It remains only to consider La Croix's final difficulty, that associated with the unfortunate case of Mr. McChin.

La Croix introduces McChin in responding to an earlier suggestion of mine, a suggestion which in this paper is replaced by (C2). There is, nevertheless, still something of interest in McChin's sad case. As described by La Croix, McChin is almost omnipotent, having every requisite power except that of scratching chins. But it seems clear to La Croix that McChin is not omnipotent, and hence that any satisfactory definition must exclude him.

Well, maybe so. Why does McChin fail of omnipotence? According to La Croix, "McChin is clearly not omnipotent since there are an indefinite number of states of affairs that he is unable to bring about, namely, all those states of affairs in which McChin scratches chins." But this is not at all conclusive. As I have already argued, the fact that we can identify some state of affairs which a certain being cannot bring about does not show that this being is not omnipotent. Such a being may still be perfectly well able to meet every legitimate challenge, and, if so, he will be omnipotent. And even apart from that argument for the moment, consider the case of a being for whom it is an essential property that he be disembodied. I.e., there is no possible world in which that being exists and has a body. That being will not be able to scratch anyone's chin, since he has no finger with which to scratch it. ${ }^{2}$ He may, however, have the power to cause every chin to be scratched (presumably McChin has this power), perhaps by creating the Amazonian Chin Scratcher, which goes about irresistibly scratching chins. Is it plausible to suppose that this being must be lacking in omnipotence simply because, though he can cause every chin to be scratched, he cannot himself scratch any of them? That seems rather implausible. I do not, therefore, find it completely obvious that Mr. McChin is not omnipotent. La Croix does not tell us whether the inability to scratch chins is an essential property of McChin - i.e., whether it is a necessary truth, or only a contingent truth, that if McChin exists he has this property. And that is crucial. 
If we were to formulate McChin's case in terms applicable to my definition we would have to find some proposition, presumably about McChin, chins, etc., and which satisfied conditions (C1) and (C2). I suppose the most plausible candidate, and the one which seems to be suggested by La Croix's discussion would be

Mr. McChin is scratching some chin.

Now, La Croix seems to think that McChin cannot bring about any state of affairs which satisfies (5). Well, maybe not. But first, is it possible that some agent should bring about a state of affairs satisfying (5)? E.g., could some other agent (God, possibly?) strengthen McChin in the requisite way and then get him to scratch a chin or two? If McChin's lamentable weakness is not one of his essential properties, then, I suppose, it is not a necessary truth that no agent can cure him of it. And if that is so, then proposition (5) meets the condition in my definition. We must then ask whether McChin himself could remedy this defect, etc. If so, then McChin can, after all, bring about some state of affairs which satisfies (5), and (5) will pose no barrier to his putative omnipotence. If, on the other hand, McChin cannot bring about the remedying of his own weakness, then he would seem to lack another power besides that of scratching chins. (That I cannot speak Russian is one thing; that I cannot learn Russian would seem to be another.) At any rate, if it is possible that someone should bring about the satisfaction of (5), but McChin cannot do so, then I agree with La Croix that McChin is not omnipotent. And my definition yields that result.

If, on the other hand, no agent could possibly bring about the satisfaction of (5) (perhaps because the inability to scratch chins is an essential property of McChin) then McChin cannot do so. But an inability to do something of which it is necessarily true that no agent can do it, is not a barrier to omnipotence. In this case, McChin may or may not fail of omnipotence for some other reason. But his inability to scratch chins, and proposition (5), will have nothing to do with it.

As I said at the beginning of this paper, the definition which $I$ have proposed may prove defective in some way, and I will be interested to see if that happens, I believe, however, that it meets La Croix's problems, and refutes his claim to have proven that a general definition of omnipotence is impossible. 
NOTES

1 As by Alvin Plantinga in The Nature of Necessity.

2 The relevance of cases like this for the concept of omnipotence was first called to my attention by Dr. Joseph Runzo. 